\title{
Sergio Moro inocentando a Alma Brasileira ${ }^{1}$ :
}

O super-homem de massas e as lógicas sacrificiais em 2016

João Marcos Copertino Pereira²

\section{Resumo:}

Este ensaio é uma reflexão sobre as implicações da narrativa super-heroica criada em torno de Sergio Moro durante seu tempo conduzindo a Operação Lava Jato. Tal caracterização contribui para a "hipervisibilidade" contemporânea, dando explicações unívocas a problemas complexos como a corrupção e a busca por justiça. O curioso é que uma simples comparação entre os livros sobre Sergio Moro e os recentes filmes de super-heróis apresenta como que a cultura de massas tem apresentado interpretações mais complicadas para a questão da justiça que as dadas por alguns jornalistas brasileiros. de Massas.

Palavras-chave: Sergio Moro - Corrupção - Vítima Emissária - Super-homem

\section{ABSTRACT:}

This essay is a reflection on the implications of the super-heroic narrative built surrounding Sergio Moro during his time conducting the Lava Jato Operation (or Car Wash Operation). His characterization contributes to the contemporary "hypervisibility" and it gives single-sided explanations for complex problems like corruption and the fight for justice. The interesting part is that a simple comparison between the books on Sergio Moro and the recent super-hero films show that mass culture presented a more complex interpretation for the justice problem than some Brazilian journalists.

Keywords: Sergio Moro - Corruption - Emissary Victim - Mass Superman.

\section{RESUME:}

Cette étude est une réflexion sur les implications des récits héroïques construits autour de Sergio Moro, quand il menait l'opération Lava Jato. Je vise à montrer que sa mythification a contribué à une " hyper visibilité " actuelle, elle donne aussi des explications simplistes pour des problèmes complexes comme la corruption et la recherche de la justice.. Ce qui est intéressant c'est que la comparaison entre la biographie de Sergio Moro et les derniers films de super-héros révèle comment la culture de masse a construit des interprétations beaucoup plus complexes que celles faites par des journalistes brésiliens concernant la question de la justice.

Mots-clés: Sergio Moro - Corruption - victime émissaire - superman massive.

\footnotetext{
1 Este ensaio tem parte das conclusões de minha dissertação de mestrado, financiada com a bolsa Erasmus+, sem este suporte financeiro, a pesquisa seria impossível.

2 Bacharel em História pela Universidade de São Paulo, mestre em Narrativas Culturais pelas universidades de Sheffield (Reino Unido), Nova de Lisboa (Portugal) e Perpignan (França). Atualmente é aluno de doutorado em Línguas românicas na universidade Harvard (Estados Unidos). Email: jmcopertinopereira@g.harvard.edu.
} 
Quando entreguei a minha dissertação de mestrado em junho do ano passado, eu não era capaz de conjecturar a entrada de Sergio Moro no governo Bolsonaro. Ainda que fosse crítico de suas ações enviesadas, eu temia que estava sendo demasiado pessimista. Ledo Engano. De maneira ingênua, não consegui perceber quão próximo estava o herói da "república de Curitiba" do "Mito". A proximidade entre os dois já se dava na estrutura da qual suas narrativas foram baseadas, inclinadas para os modelos de super-homem de massas (Eco, 1991) e salvadores da pátria (Girardet, 1986). Era só uma questão de gramática narrativa do discurso político. Neste ensaio defendo que as biografias sobre Sergio Moro laçados em 2016 embasaram uma narrativa antidemocrática, explorando o desejo de expiação de culpa de uma parcela significativa da população brasileira. A representação de Moro como um super-homem massas é imprescindível para compreendermos seu grande apelo midiático, demonstrando a nitidez interpretativa simplificadora que muitos têm usado ao discutirem a política contemporânea.

Antes de tudo, friso que a criação dos heróis nacionais é processo longo e recheado de debates. Especificamente no caso brasileiro, temos um panteão bem mais sucinto que o dos nossos vizinhos latinos ou anglo-saxões. Principalmente após a derrocada de Fernando Collor, os sinais do culto da nação por meio de heróis são diminutos. Algumas das moedas são estampadas por homens, sempre brancos, que são retratadas de forma idealizada, sem problematizações. Os signos que tem embasado a nacionalidade são outros: telenovela, futebol, samba, malandragem, etc. No entanto, quando se fala de heróis, o caso de Tiradentes é exemplar. Uma das poucas figuras que possui um feriado para chamar de seu, o inconfidente teve sua imagem cotejada por quase um século para então adentrar o imaginário nacional (Carvalho, 1990). Nos quase cem anos que se passaram entre a sua pena de morte e a clássica pintura de Pedro Américo, Tiradentes teve seu legado transmutado de regionalista rebelde, para defensor de um processo revolucionário nacional e republicano. Existe uma construção de imaginário que se fia numa aura mítica deveras comprometida com o momento presente. Acredito que foi nesse mesmo tipo de heroísmo místico-nacional que afoitamente Joice Hasselmann e Vladimir Netto tentam enquadrar Sergio Moro. 


\section{REVISTA PENSATA | V.7 N.1}

\section{DEZEMBRO DE 2018}

O então juiz Sergio Moro foi biografado em dois livros de 2016 que pecam por uma falta de verossimilhança abismal. É uma construção demasiadamente idealizada, na qual o juiz não teria passado por nenhum conflito psicológico. Ele seria um homem obtuso, que preza a solitude, possuidor de um ímpeto moral tamanho que leva a momentos vexatórios a qualquer leitor com um mínimo de cinismo. Tanto Joice Hasselmann, quanto Vladimir Netto enfatizaram a personalidade mão firme de Moro. É num desses momentos que Netto relata como o professor Moro quase reprovou Rosângela - que viria a ser sua esposa - por excesso de faltas na faculdade. A construção da narrativa de Netto faz com que não existam culpados. Rosângela não foi às classes porque acreditou que a disciplina não estava sendo oferecida, quando o descobriu, já havia ultrapassado o limite aceitável de faltas no curso. No meio do semestre, teria que ir ao casamento de uma amiga no horário da aula. Não o pode. $\mathrm{O}$ professor ameaçou reprová-la em seu último ano de faculdade caso ela faltasse numa aula sexta-feira à noite. $O$ espaço para emoção e julgamento se concentra na voz de Rosângela ("Eu detestava ele, detestava", Netto, 2016, p. 45) e, num tom mais baixo, na do narrador ("[o] professor exageradamente rígido" itálicos meus, idem, p. 46). Ainda assim, existe uma demonstração de como Moro possuiria uma moral espartana, algo que de certa forma o qualificaria para a toga.

Se o super-herói dos quadrinhos é definido por superpoderes como voar, força, leitura de mentes, e por aí vai, Sergio Moro teria uma capacidade fora da média para a magistratura. É por meio de um exímio domínio das leis que o juiz conseguiria manter a viabilidade da Lava Jato, peitando ações de juízes do supremo, dificuldades legais, pressões petistas, etc. Um bom exemplo é como Vladimir Netto narra a resolução de Moro a um dos primeiros entraves da operação Lava Jato em 2014. O ministro Teori Zavascki questionou a competência da primeira instância para o julgamento de Paulo Roberto Costa, a "tensão era grande na $13^{\mathrm{a}}$ Vara da Justiça Federal" e "o clima de inquietação também já se espalhara pelos corredores" (Netto, 2016 , p. 52), oposto a euforia generalizada, Sergio Moro se identificava por sua reclusão e calma:

Alheio a tudo, Sergio Moro continuava trancado em seu gabinete. A câmera de segurança no canto do teto da sala do juiz só registrava seu trabalho silencioso ao computador. Logo o texto estava pronto. Moro foi muito cuidadoso no texto (Idem, p. 52). 
O ofício de Moro se caracterizava por ser uma manobra arrojada, na qual não se questionava a autoridade do Supremo, mas também não acatava a decisão de Brasília. O juiz pedia uma sugestão de como proceder para a instancia superior. Seria "um gesto incomum. Alguns juízes jamais tentariam" (Idem, p. 53). São nesses momentos que os elementos básicos para a caracterização de um super-homem de massas se fazem presentes, existe uma ênfase na individualidade e distinção do herói, ao mesmo tempo que se destacam as suas grandes capacidades, sejam físicas ou intelectuais.

Em diversos momentos da narrativa de Netto, Moro é descrito como um homem de habilidades extraordinárias, distinguindo dos demais procuradores e juízes. $\mathrm{O}$ narrador imbuiu ao juiz o fardo de ser um dos poucos capazes de resolver a crise moral da nação. Se a aproximação com o super-homem de massas no texto de Netto é algo se dá por meio das ações, se avaliarmos narrativas ainda mais afanadas, observamos como o tema do heroísmo se torna ainda mais ululante. Ainda que Joice Hasselmann diga que Moro não possui superpoderes, mas "apenas coragem, trabalho, dedicação e retidão" (Hasselmann 2016, p. 183), ela não excitou em chamar o juiz de 'herói' em diversos momentos da narrativa. Não somente isso, como o relaciona ao heroísmo dos quadrinhos a própria construção da personalidade de Moro (Idem, p. 128-129). A autora também qualifica Joaquim Barbosa como uma forma de Batman de nossa política (Idem, p. 76), ou seja, a relação entre super-heroísmo e combate à corrupção é um recurso narrativo recorrente em sua obra. Além de práticas textuais, na própria construção imagética, Moro é retratado como um herói, seja na capa dos livros ou no seu pixuleco que andou as ruas do país. Enquanto na capa do livro de Netto o busto de Moro é retratado no majestoso contra-plongée, no livro de Hasselmann o juiz é conectado ao elemento nacional, com a bandeira ao fundo, ainda que a foto de perfil seja menos imponente. A única coisa que os dois livros não concordam é a grafia do nome do juiz, para Hasselmann é Sérgio, para Netto é Sergio.

Encaixar Sergio Moro dentro do arquétipo de super-homem de massas explicita uma forma de se fazer justiça muito específica, na qual a população se torna parte passiva e vitimizada. De acordo com Umberto Eco (1991), o super-homem de massas seria das mais eficientes formas de consolar a população pela subtração da justiça 


\section{REVISTA PENSATA | V.7 N.1}

\section{DEZEMBRO DE 2018}

em sua vida cotidiana, em outras palavras, a injustiça continuamente vivenciada poderia ser vencida, ao menos, no campo da ficção (Idem, p. 62). O método de vencer essa brutal imoralidade seria a confiança no poder de uma pessoa que se apresente como idealmente capacitada, daí a alienação de mundo clássica da literatura de super-herói. Para Eco, a confiança num individuo superdotado desprivilegia um debate político, pois o super-homem de massas ignora se as plebes oprimidas têm a capacidade de julgar por conta própria (Idem, p. 95). Nos termos do nosso debate, o uso da figura dos super-homem de massas não necessariamente aliena a população do debate político, mas certamente as inocenta, colocando-as como vítimas de opressões de maus provocados por políticos de alto-escalão. Veja bem, se estamos lidando com super-homens de massa, estamos também lidando com antagonistas à altura, o que foi bem claro na retratação do Super Moro. O antagonista é o petismo, e suas figuras são os políticos de destaque: Lula, Dilma, José Dirceu, Gleisi Hoffmann, etc.

A justiça do super-homem de massas é nítida, tem concepções binárias da verdade e personifica o mal. Enquanto a verdade una simplifica a interpretação da realidade em discursos esquemáticos nos quais a oposição é impossível, a personificação do mal permite a expiação da nacionalidade brasileira como um todo:

O que a Lava Jato, o juiz Sergio Moro e os investigadores estavam dizendo ao longo dos meses, com atos e palavras, é que a corrupção não está na essência da alma brasileira. Há um sistema que favorece o êxito dos corruptos - e o fracasso dos honestos. Em outros países foi possível mudar isso. O desafio fora lançado. Mas a batalha estava longe do fim. Era preciso atacar de vez o lado mais poderoso do problema: o núcleo político do esquema (Netto, 2016, p. 220, meu grifo).

A ideia de que a alma brasileira estaria livre de corrupção - o problema seria alguns maus elementos -, se opõe a interpretações sociológicas de renome como a de Sergio Buarque de Hollanda (1936) e Céli Pinto (2011). Ainda que muito diferentes entre si, essas linhas interpretativas apresentam como que a corrupção é democratizada em nosso país. Os crimes cometidos pelos políticos na esfera federal são a ponta do iceberg de um sistema social que é condescendente com práticas imorais.

Veja bem, a ideia de expiar a culpa da população brasileira não é simplesmente presente nos dois livros sobre Sergio Moro, Bruno de Carvalho (2018) mostrou como 


\section{REVISTA PENSATA | V.7 N.1}

\section{DEZEMBRO DE 2018}

este discurso de "não foi você" foi essencial no fenômeno do Bolsonarismo por WhatsApp. Para Carvalho, a isenção de culpa do individuo brasileiro foi um fenômeno recompensador para os eleitores de 2018. No caso de Sergio Moro, essa isenção caminha com a confiança no juiz para determinar quem seria o real culpado, no caso de Bolsonaro, o seria num combate do 'inimigo' por meio dos instrumentos do poder executivo. Ao menos neste tópico, teste David cum Sybilla atestam que o mote é estabelecer nitidamente que quem se alia ao lado de Moro e Bolsonaro seria inocente. É essa gramática narrativa política que uniu o Mito e o Superministro.

Entretanto, se nós acreditamos que a banalidade da corrupção no Brasil se dá tanto pela ação de indivíduos, como por instituições sociais que permitem a continuidade e modernidade da imoralidade política, por consequência acreditamos que a culpa da situação deve ser sociabilizada, ou seja, todos são responsáveis em maior ou menor grau. Ao estabelecer que a culpa é individualizada a um seleto grupo de políticos de alto-escalão, estamos lidando com um processo de transferência de culpa. A questão é entender como que esta transferência é realizada.

O que defendo é que esse processo de isenção de culpa da alma brasileira caminha por uma resolução das questões políticas dentro dos parâmetros da lógica sacrificial, nos termos definidos pelo filósofo René Girard (2016). Para ele, a mola interpretativa fundamental no sacrifício é a vítima emissária ${ }^{3}$. Simplificando o complexo jogo analítico de Girard, a vítima emissária é a pessoa que fica no centro do debate da crise sacrificial. Ao fim da crise, ela o é sacrificada por representar tanto a monstruosidade de seus erros, como pela transferência dos erros cometidos por toda a sociedade. Em outras palavras, a vítima emissária sofre tanto uma violência diferenciada, aquela que é definida por seus crimes, como uma violência indiferenciada, derivada dos crimes de todo o grupo social. Importante ressaltar o papel da crise sacrificial em si, pois, ao princípio do processo, não há culpados prédeterminados, mas sim um debate político que visa estabelecer qual seria a vítima que mais se adequaria para ser punida com a violência indiferenciada. O processo que não é nem um pouco nítido no princípio, vai se esclarecendo no decorrer da crise.

${ }^{3}$ Girard escreveu extensivamente sobre a ideia de vítima emissária e bode expiatório em diversos livros, os termos, ainda que semelhantes, não são sinônimos. 


\section{REVISTA PENSATA | V.7 N.1}

\section{DEZEMBRO DE 2018}

Em La Violence et le Sacré, René Girard primou pela interpretação da lógica mítico-sacrificial conjugando com o esquema da tragédia ática, então ele elabora o conceito junto a sua particular análise da peça de Sófocles, Édipo Rei. O herói que ao fim é metaforicamente sacrificado, ao princípio é julgado tão inocente quanto Creonte. A busca pelo assassino de Laio não implica somente na punição do regicídio, mas sim uma busca para sanar as desgraças de toda a Tebas, destarte, a morte do assassino do rei significa um castigo que extrapola o crime originalmente cometido. Essa vítima emissária deve representar esses crimes dos quais os efeitos afligem toda a cidade de Tebas, ou seja, os crimes cometidos por Édipo, seu parricídio e incesto, o qualificam para ser o receptáculo de todos os outros infortúnios da cidade, dos quais Édipo teve pouca ou nenhuma influência. Não menos importante, enquanto a crise sacrificial ainda estava em seu momento de debate, Édipo defendia semelhante punição para Creonte, ou seja, ele não tinha problema algum com a lógica sacrificial em si, tanto que aceita seu papel como vítima de forma trágica, mas formidável.

Agora, aproximando ao caso em questão, a ideia é que as capacidades jurídicas de Sergio Moro conjugam tanto a violência diferenciada, legítima perante a justiça moderna, e a violência indiferenciada, da qual não há legitimidade constitucional, mas sim literária. As biografias sobre Moro o qualificam como homem ideal para liderar o ritual, daí se estabelece o sacerdote e o sacrifício. Ao culpar um grupo fechado de políticos de alto-escalão, o leitor que fiou no julgamento de Moro consegue sua inocência. A realidade é simplificada e "todos os rancores espalhados pelos mil diferente indivíduos, todos os ódios divergentes, vão convergir em um único indivíduo, a vítima emissária" (Girard, 2016, p. 122, minha tradução)4. O super-homem se torna o único capaz de julgar quem pode ser culpado por tudo que desola o país, assim, por meio do sacrifício, ele inocenta a alma brasileira.

Veja bem, não que os réus políticos de Moro não sejam de todo culpados, eles cometeram crimes, contudo, a punição deles simboliza uma ambição e um fardo muito maior do que seria possível dentro das lógicas jurídicas modernas. O próprio afã social

4 No original: «Toutes les rancunes éparpillées sur mille individus différents, toutes les haines divergentes, vont désormais converger vers un individu unique, la victime émissaire » (Girard, 2016, 122, itálicos do texto). 


\section{REVISTA PENSATA | V.7 N.1}

\section{DEZEMBRO DE 2018}

na condução dos processos da Lava Jato mostra como que existe uma vocação punitiva que extrapola qualquer tipo de punição possível no nosso sistema legal. Mais do que isso, justamente por essa vocação sacrificial da operação Lava Jato, a frustração com a condução dos processos na longa duração parece ser algo certeiro. O que fica de consolador nos livros sobre Sergio Moro é a nitidez interpretativa da realidade e defesa que ainda existem heróis capazes de fazer todo o trabalho punitivo por nós, desde que dediquemos a eles uma confiança cega.

O curioso é que essa nitidez interpretativa da verdade e da punição tão descarada na representação de Sergio Moro, ao menos até 2017, tem sido questionada no que há de mais representativo de mass culture atualmente, os filmes de super-heróis da Marvel. Ainda que não de forma uniforme, os filmes recentes da Marvel têm apresentado uma complexidade no julgamento da realidade. Nas tramas há confrontos contínuos entre os heróis, e vilões cujas as motivações são tão dignas que fica difícil entender complemente a vilania dos mesmos. Se é típico do contemporâneo uma "hipervisibilidade" (Baudrillard, cf. Wisnik, 2018, p. 87), no qual tudo é muito claro, nítido, certo e preciso, eu aponto como que o nublamento, tão caro a arquitetura (Wisnik, 2018, p. 5), tem se apresentado de forma interessante na Marvel. A figura do super-herói tem sido apropriada para demostrar conflitos internos e debates relevantes sobre o como fazer justiça.

O filme Captain America: Civil War de 2016, mesmo ano das biografias de Sergio Moro, apresenta um conflito fora do usual da Marvel, mas antes de falar, é preciso ressaltar: ALERTA DE SPOILER. Ao contrário da usual destruição massiva de Nova lorque, Civil War tem seu momento de tensão máxima com o conflito entre o Homem de Ferro e o Capitão América dentro de uma instalação da Hydra no ermo da nublada Sibéria. O confronto não pode ser interpretado entre o bem e o mal, mas entre dois heróis que tem discordâncias graves na forma da qual suas atividades heroicas devem ser conduzidas. Assim, a questão se torna complexa e se debate a relação entre o super-heroísmo e a intervenção estatal. Enquanto Tony Stark entende que suas ações possuem implicações negativas para a sociedade, e busca uma forma de fiscalização e autorização de suas ações pelo Estado, Steve Rogers prima por sua liberdade de ação, pois ele também teme a instrumentalização de seus poderes pelo 


\section{REVISTA PENSATA | V.7 N.1}

\section{DEZEMBRO DE 2018}

Estado para usos nefastos. O conflito é interno ao grupo de heróis, e a resolução do confronto não corrobora na inocência de alguém, mas sim numa medida preventiva sobre as formas de ação. O simples fato que a própria capacidade de justiceiro do herói é questionada, faz com que um filme da Marvel apresente noções muito mais complicadas do que seria certo ou errado que qualquer livro panfletário sobre a Lava Jato. Se dá à realidade uma falta de visibilidade ao espectador, algo que está ausente no atual discurso político brasileiro, os nossos confrontos têm-se caracterizado por interpretações unívocas e pouco diálogo. FIM DO SPOILER.

Enquanto nosso vocabulário político tem buscado um retorno a lógica míticoheroica massiva, os setores que seriam responsáveis pela propagação desta mesma lógica, os grandes filmes hollywoodianos, têm possuído interpretações mais complicadas. Escrevi sobre Captain America, mas em maior ou menor grau, esta complexidade interpretativa tem se tornado a norma da Marvel, vide a complexidade do vilão em Black Panter (2018). No caso de Sergio Moro, é interessante notar como as lógicas míticas, tão importante de serem analisadas tanto em suas conexões universais, como particulares, têm sido utilizadas como instrumento simplificador, visando expiar uma população que foi responsabilizada por diversos problemas sociais durante muito tempo. Sergio Moro entraria no panteão nacional, não pelo seu combate a corrupção, mas sim pela sua saga em inocentar, ao mesmo em tese, a alma brasileira.

\section{REFERÊNCIAS BIBLIOGRÁFICAS}

BUARQUE DE HOLLANDA, Sérgio. Raízes do Brasil. Rio de Janeiro: José Olympo, 1936.

CARVALHO, Bruno "Não foi você: uma interpretação do bolsonarismo". In: Revista Piauí, no. 142. Rio de Janeiro: Editora Alvinegra, Julho de 2018.

CARVALHO, José Murilo. A Formação das Almas: o imaginário da República no Brasil. São Paulo: Companhia das Letras, 1990.

ECO, Umberto. O Super-homem de massas: retórica e ideologia no romance popular. (trad. Pérola Carvalho). São Paulo: Perspectiva, 1991.

GIRARD, René. La Violence et Le Sacré. Paris : Pluriel, 2016 (orig.1972). 


\section{REVISTA PENSATA | V.7 N.1}

\section{DEZEMBRO DE 2018}

GIRARDET, Raoul. Mythes et mythologies politiques. Paris : Éditions du Seuil, 1986.

HASSELMANN, Joice. Sérgio Moro: a história do homem por trás da operação que mudou o Brasil. São Paulo: Universo dos Livros, 2016.

NETTO, Vladimir. Lava Jato: O juiz Sergio Moro e os bastidores da operação que abalou o Brasil. Rio de Janeiro: Primeira Pessoa, 2016.

PINTO, Céli. A Banalidade da Corrupção: uma forma de governar o Brasil. Belo Horizonte: Editora UFMG, 2011.

WISNIK, Guilherme. Dentro do Nevoeiro: Arquitetura, Arte e Tecnologias Contemporâneas. São Paulo: Ubu Editora, 2018. 